\title{
An Overview of Cloud Services Adoption Challenges in Higher Education Institutions
}

\author{
Abdulrahman Alharthi, Fara Yahya, Robert J Walters and Gary B Wills \\ Electronics and Computer Science, University of Southampton, Southampton, United Kingdom \\ \{aaa2g14, fby1g14, rjw1, gbw\}@ecs.soton.ac.uk
}

Keywords: Cloud Services Adoption, Challenges, Cloud Computing, Higher Education, Integrated TAM model

\begin{abstract}
Information Technology (IT) plays an important role in enabling education services be delivered to users. Most education online services in universities have been run on the cloud to provide services to support students, lecturers, researchers and administration staff. These are enabled with the emergence of cloud computing in the world of IT. Cloud computing offers on demand Internet-based computing services. This paper presents an overview of cloud computing adoption in higher education, mainly tertiary institutions and universities. The focus of the paper is the challenges of cloud computing in higher education. It introduces the background to cloud computing and reviews research on adoption challenges in higher education institutions. These challenges are important as they provide an overview of the adoption of cloud in higher education. The authors proposed an integrated reference model based on the challenges in the literature integrated with TAM model to investigate the factors influence the users' attitudes and behaviours toward using cloud education services in universities ICT provision.
\end{abstract}

\section{INTRODUCTION}

In recent years, the Internet has accelerated the use of cloud services to support education online system. The cloud has become the main backbone in enabling such services by providing facilities to users. Cloud computing is known as a recent model that enables users to have computing resources on demand and pay per use (Sultan, 2010). It has been used widely in education; educators and students store and share their data widely in the cloud (Sultan, 2010). Previously, data were kept in external hard drives or storage servers in a location having restricted access in private networks. Nowadays, data can be stored in the cloud allowing accessibility to data to be more flexible and efficient.

Previous research has shown many aspects of cloud computing have been studied in the area of education, technology, education information systems (Alshwaier, 2012), integrating education resources and education system development (Huang, 2012). Smaller educational institutions often lack the resources or abilities to take full advantage of information technology. Cloud computing offers opportunities to improve the quality of education by offering flexibility and accessibility through the Internet. This can enable more dynamic and interactive learning experiences and allow students and teachers in multiple locations to collaborate and communicate more effectively (Alabbadi, 2011). In addition, cloud-based services can offer users and academic institution cost savings and access to scalable computing power (Buyya, Broberg and Goscinski, n.d.; Armbrust et al., 2009; Motta, Sfondrini and Sacco, 2012).

\section{BACKGROUND}

This section presents the backgroud of cloud computing definitions, models and characteristics. Cloud computing computing is defined by the National Institute of Standards and Technology (NIST) as a model for providing a provisioned and on-demand computing resources which includes 
networks, servers, storage, applications, and services. It can be accessed using the Internet and needs minimal management effort or interaction from the cloud service provider (CSP) (Mell and Grance, 2011). Cloud computing is delivered at levels offering software applications, application platforms or various infrastructure elements as cloud systems. According to NIST (Mell and Grance, 2011), cloud computing has three service models:

- Software as a Service (SaaS): the entire system is cloud based, so users are presented with the application(s) only.

- $\quad$ Platform as a Service (PaaS): suitable for user intending to deploy their own applications

- Infrastructure as a Service (IaaS): provides cloud based infrastructure such as storage, processing and networking elements.

Cloud computing is usually deployed in four models (Mell and Grance, 2011), Private Cloud, Community Cloud, Public Cloud, and Hybrid Cloud.

\section{CLOUD IN HIGHER EDUCATION INSTITUTIONS}

Higher Education institutions play an important role in the growth of societies. As with organisations nowadays, universities have become more reliant on Information and Communication Technology (ICT). ICT and internet-based services have to provide their stakeholders with educational services. Cloud computing is likely to be an attractive proposition to start up and small to medium educational establishments. The potential of cloud computing may include but is not limited to increasing service efficiency and cost-savings. An example from the University of California (UC) at Berkeley, found cloud computing to be attractive for use in one of their courses which was focused exclusively on developing and deploying SaaS applications (Alshwaier, 2012).

The Medical College of Wisconsin Biotechnology and Bioengineering Centre in Milwaukee found the use of cloud computing in their research has provided an astounding computing power. Researchers at the centre have been doing protein research which has been made more accessible to scientists from anywhere in the world. This is due largely to renting Google's cloud-based servers (Sultan, 2010).

Some universities have adopted cloud computing for economic reasons. The Washington State University's School of Electrical Engineering and Computer Science (EECS) has suffered cuts in its budget. However, the EECS claims that despite the challenging economic climate, cloud computing has actually enabled it to expand the services it offers to faculties and students (Sultan, 2010).

Some Universities are facing difficulties to provide scalable and flexible IT services. For instance, in traditional computer labs, there are many challenges present such as, limitation of lab hours and seats during the peak hours, repairing and maintaining computer labs, traveling to and from university, cost of outfitting traditional computer lab (hardware and software). Normally, IT services required by students, researchers and academic are requested from the IT Department, whose job is illustrated in Figure 1.

The IT department provides students, staff, academics and developers with different software and hardware tools. However, in cloud computing all these arrangements can be migrated to the cloud (Sultan, 2010). Figure 2 illustrates an example of how cloud computing is used in the university.

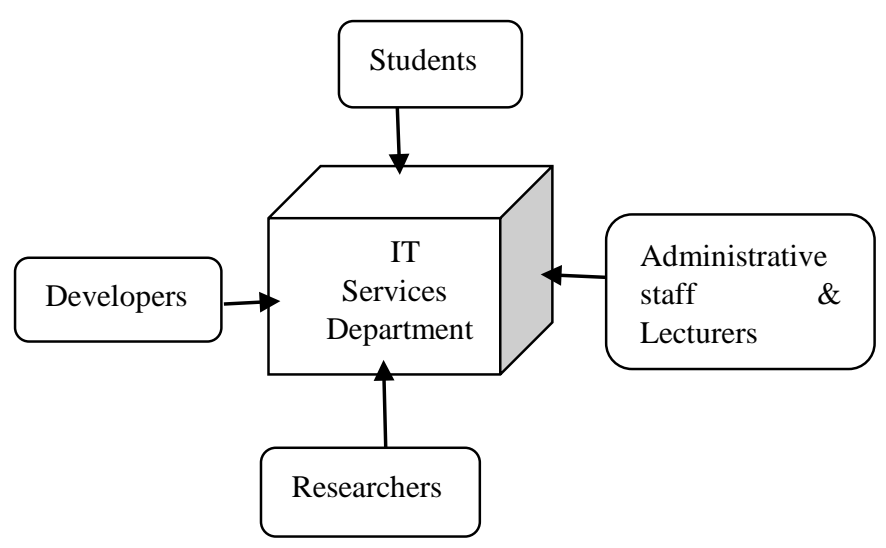

Figure 1: Users of Traditional IT services in a University (Sultan, 2010).

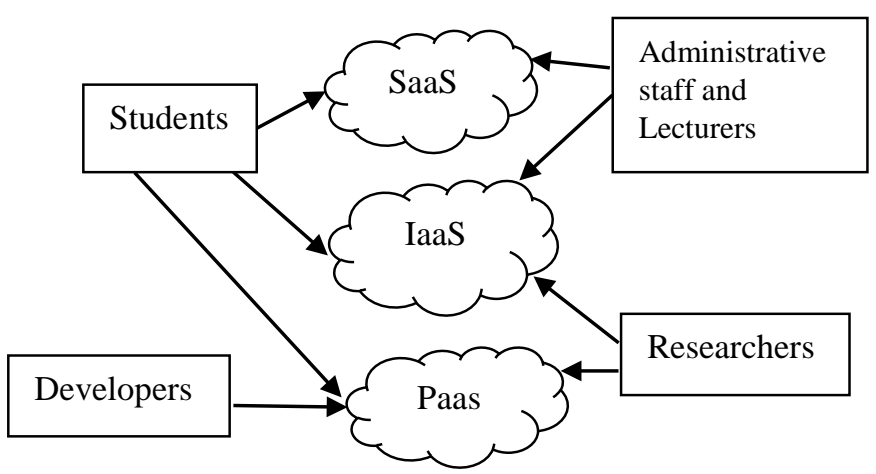

Figure 2: Cloud computing service models in a University (Mathew, 2012).

Cloud Computing offers services that enable the universities to concentrate more on teaching and research activities rather than building on complex IT configurations and software systems (Sultan, 2010). It can also be deployed more quickly. Complexity can be reduced with Cloud Computing. Students can exploit different learning tools. Students already use some, such as Google Docs and Office365 and 
Windows Azure Platform for computer science students (Ercan, 2010). Students can access the learning resources they need from anywhere and at any time with any Internet capable device.

Lecturers may experience flexible benefits as the cloud provides an easier platform to prepare their teaching portfolio presentations, lessons, conferences, articles, etc. Researchers may also benefit from the advantages of using the latest technologies and hardware to do their experiments, while paying for using these services only on demand (Mircea and Andreescu, 2011).

Developers can design, build and test applications on the infrastructure of the cloud service provider and produce those applications from cloud provider data centres to the end user (Sultan, 2010; Huang, 2012) System administrators can leverage processing, storage, database management and other resources available on the cloud.

\section{CLOUD SERVICES IN HIGHER EDUCATION}

The trend of educational cloud computing has been adopted by many leading IT companies. Microsoft, Google, Amazon and IBM have provided much initiative to support education institutions with the necessary learning tools. Some of these initiatives are free with no cost. Table 1 shows some of the existing educational clouds and tools. With the availability of content online, it is unnecessarily for lecturers to print teaching materials. Nowadays, students have the choice to access homework assignments, lesson notes, and other materials online with the cloud. Some of the leading cloud services in higher education are described below.

\section{- Microsoft Education Cloud}

Microsoft Education Cloud has been actively developing educational cloud services such as Microsoft Office 365. It provides schools with free email, website with editing and storage facility, instant messaging, web conferencing, and 25 GB of personal storage (Jay, 2014). Furthermore, students and faculty are able to use any browser to create documents using Microsoft Office (David, 2013).

The downside to Microsoft 365 is the cost. While a free option is available (with a signed contract), a peruser monthly payment is required to access features such as Office Mobile, Office applications for PC or Mac, unlimited email storage and voicemail. More alarming is Microsoft's inability to ensure 99.9\% uptime without monthly payment (Jay, 2014).

\section{- Google Education Cloud}

Google Apps for Education is one of the most used application as it does not involve actual cost (Jay,
Table 1 Examples of educational cloud-based applications (Abdul Razak, 2009; Alshwaier, 2012)

\begin{tabular}{|l|l|l|}
\hline $\begin{array}{l}\text { Commercial } \\
\text { Product } \\
\text { Name }\end{array}$ & $\begin{array}{l}\text { Education } \\
\text { cloud apps }\end{array}$ & Features \\
\hline $\begin{array}{l}\text { Microsoft } \\
\text { Education } \\
\text { Cloud }\end{array}$ & $\begin{array}{l}\text { Microsoft } \\
\text { Live@edu }\end{array}$ & $\begin{array}{l}\text { Website Creation } \\
\text { File sharing } \\
\text { Word processing } \\
\text { Desktop sharing } \\
\text { Resource } \\
\text { scheduling }\end{array}$ \\
\hline $\begin{array}{l}\text { Google } \\
\text { Education } \\
\text { Cloud }\end{array}$ & $\begin{array}{l}\text { Education } \\
\text { (GAE) }\end{array}$ & $\begin{array}{l}\text { Google Mail } \\
\text { Google Sites } \\
\text { Google Docs } \\
\text { Google Video } \\
\text { Google Calendar } \\
\text { Google Talk }\end{array}$ \\
\hline $\begin{array}{l}\text { Earth } \\
\text { Browser }\end{array}$ & Earth Browser & $\begin{array}{l}\text { Provide real } \\
\text { Time data for } \\
\text { weather, } \\
\text { geological and } \\
\text { other data }\end{array}$ \\
\hline VMcademy & $\begin{array}{l}\text { Virtual } \\
\text { Desktop }\end{array}$ & $\begin{array}{l}\text { Provide Virtual } \\
\text { science to access } \\
\text { Create and study } \\
\text { modules }\end{array}$ \\
\hline & Socratica & $\begin{array}{l}\text { Smart analytics } \\
\text { system }\end{array}$ \\
\hline
\end{tabular}

2014). It is free with no hidden costs. Some of the feature include cloud email, 30GB of storage, hosting, word processing and collaboration tools (Google, 2015). Google is Microsoft's strongest competitor. If it is compared to Microsoft's Office Suite, there is an existing familiarity with many of Google's products such as Gmail, Chat, and Calendar. Nevertheless, the main drawback is that it requires users to have (or create) a Google account. It is compulsory for user of age 13 years old and below to get parent consent.

\section{- Earth Browser}

Earth Browser is a virtual globe software developed by Lunar software. It is available online as a flash application or be installed locally as an application (EarthBrowser, 2015a). It focuses mainly on visualising geophysical information such as weather, earthquakes, etc. It shows the earth as satellite images. EarthBrowser can be used in real-time. It is 
shows the object in three dimensional model with continuously updates information (EarthBrowser, 2015b). The representation of the earth is rendered along with a large data which is said to be accurate. The object can also be rotated and zoomed to a given distance.

\section{- Socratica}

Socratica produces high-quality educational videos for people of all ages (Socratica, 2015). The videos developed are high-definition, clear, concise, and beautiful. Socratica collects and organizes the best free educational videos into topics that can be used by users. Socratica's mission is to organise educational videos. This can be used by users to create optimised learning experience. They have also restricted videos suitable for age groups by having different channels in YouTube.

\section{- Virtual Desktops}

In computing, a virtual desktop is known as another user interface that is able to provide user with the virtual space of a computer's desktop environment through the use of a software application installed in a user's physical computer. (VMware, 2015). Generally, there are two ways to expand the virtual area of the screen. The virtual desktop are switchable allowing user to create virtual copies of their desktop that is switchable. This can be done with open windows existing one desktops.

Another approach can expand the size of one virtual screen more than the physical viewing device. Usually, navigating an oversized virtual desktop is viewed using scrolling/panning into the subsection of the virtual desktop. One of the most popular VMware product is VMware Horizon 6. It provides a virtual desktop infrastructure (VDI) platform that provides virtualized and remote desktops and applications system through one platform, enabling users access to their online resources through one integrated workspace (VMware, 2015).

\section{- IBM cloud academy}

IBM cloud academy is a collaborative community of leaders in education. It is intended for educational institutions, with a goal to help reduce costs and optimise services while making information available, and secure if needed (IBM, 2014). It can also be used to consolidate resources, improve student success, and accelerate scientific discoveries. On the management part, it is expected to add administrative efficiencies, and conserve resources.

These are known as how cloud can help educational institutions to provide services. They are actively integrating cloud technologies into their infrastructures to share best practices in the use of clouds and to collaborate with partners to create innovative cloud technologies and models (IBM, 2014).

\section{CLOUD COMPUTING ADOPTION CHALLENGES IN HIGHER EDUCATIONS}

Despite the flexibility, scalability, on demand and powerful recourses cloud computing paradigm offers the higher education institutions, there is a low rate adoption of cloud computing in higher education institutions according to Gartner evaluation. Gartner mentioned that only $4 \%$ is the existing usage of cloud services in education. Another study highlights that $12 \%$ of the participants are not familiar with cloud computing services whereas $88 \%$ of them agree that cloud computing education services must be exploited in the schools (Kurelovi, Rako and Tomljanovi, 2013). However, migration to the cloud may not be an easy task overnight. The higher education institutions face several challenges that hinder adopting cloud computing. Researchers have highlighted many factors that affect universities' decisions to adopt cloud computing as shown in Table 2. The challenges are described in the section below.

\subsection{Security}

Security in cloud computing is a major concern faced in the adoption of cloud computing, not only in academic institutions but in all industries. Cloud providers must maintain confidentiality, integrity and availability (CIA) by establishing security requirements to satisfy educational cloud computing systems. Some of these requirements are identification and authentication accounts for students, faculty members and administration staff to verify and validate each individual by username and password. Some need control permissions, priorities and resource ownership (authorisation). Encryption techniques should be employed to protect sensitive data of institution such as exams, grades, etc. from tampering or unauthorized access. There is also need to ensure non-repudiation is some circumstances which means the transactions cannot be denied using time stamps, digital signatures and confirmation receipts (Abdul Razak, 2009; Ketel, 2014; Sultan, 2010; Mathew, 2012; Alshwaier, 2012). 
Table 2 Adoption Challenges in Higher Education

\begin{tabular}{|l|c|c|c|c|c|c|c|c|}
\hline \multicolumn{7}{|c|}{ Cloud Computing Adoption Challenges in Higher Education } \\
\hline \multicolumn{1}{|c|}{ Authors } & Security & Privacy & $\begin{array}{c}\text { Lock- } \\
\text { in }\end{array}$ & Reliability & Bandwidth & Management & Trust & Acceptance \\
\hline $\begin{array}{l}\text { (Abdul Razak, } \\
\text { 2009) }\end{array}$ & $\sqrt{ }$ & $\sqrt{ }$ & & & & & $\sqrt{ }$ & \\
\hline $\begin{array}{l}\text { (Sultan, 2010) } \\
\text { 2012) }\end{array}$ & $\sqrt{ }$ & $\sqrt{ }$ & $\sqrt{ }$ & $\sqrt{ }$ & & & & \\
\hline (Mathew, 2012) & $\sqrt{ }$ & $\sqrt{ }$ & $\sqrt{ }$ & $\sqrt{ }$ & $\sqrt{ }$ & $\sqrt{ }$ & & \\
\hline (Ketel, 2014) & $\sqrt{ }$ & & & & $\sqrt{ }$ & & $\sqrt{ }$ \\
\hline $\begin{array}{l}\text { (Shakeabubakar, } \\
\text { 2015) }\end{array}$ & & & & $\sqrt{ }$ & & & $\sqrt{ }$ & \\
\hline
\end{tabular}

\subsection{Privacy}

Privacy in higher education ensures sensitive data are protected from unauthorised and unauthenticated access in the cloud. Student's records, researchers' intellectual property should be maintained on the cloud. To protect the privacy of personal data European Union (EU), has privacy regulations that prohibit the transmission of some types of personal data outside the EU. This issue has required companies such as Amazon and others to provide offerings of storage facilities located in the EU. Regulation compliance impedes some higher education from adopting cloud-computing paradigm (Abdul Razak, 2009; Sultan, 2010; Mathew, 2012).

\subsection{Lock-in}

Vendor lock-in means that the university or institution using cloud services from one provider may find all data they store and apps they use are locked-in to the products of specific provider which implies risks and significant costs to migrate to another vendor or to revert to on-premises traditional IT systems (Alshwaier, 2012; Sultan, 2010).

\subsection{Reliability}

Reliability has also been an issue for cloud users. For example, in February 2008, Salesforce.com customers were without service for 6 hours while Amazon's S3: simple storage service and EC2 experienced 3 hours outage in the same month a few days later and 8 hours outage in July. An outage is the absence of the Cloud service. Outage of the services in Higher education institutions can disrupt students from learning and can affect the learning schedule for the classes. It was mentioned that an $100 \%$ availability is impossible (Mathew, 2012; Sultan, 2010).

\subsection{Bandwidth}

Internet bandwidth is the backbone of the internet-based educational services. The quality of service relies on the connection speed, which can require investment in the network infrastructure (Ketel, 2014; Mathew, 2012).

\subsection{Management}

There are differences between traditional education management and education management with cloud computing. Hence, implementing cloud computing will lead to management challenges such as how to manage teaching and learning, the content and courses, the examinations and students $[9,14]$.

\subsection{Trust}

Trust of online services is one of the most challenging factors in academia. In 2013, a research was conducted in Malaysian Universities (Shakeabubakor, 2015), which were UKM, UTM, UM, and UNITEN. The study aim was to investigate the researchers needs of productivity tools based on cloud computing in their reserch practices. The authors conducted interviews with researchers and postgraduate students. One of the significant findings was that $89 \%$ of the interviewed researchers distrust cloud application in their research activities (Shakeabubakor, 2015; Abdul Razak, 2009). 
Figure 3 A proposed integrated model for cloud computing adoption in higher education institutions

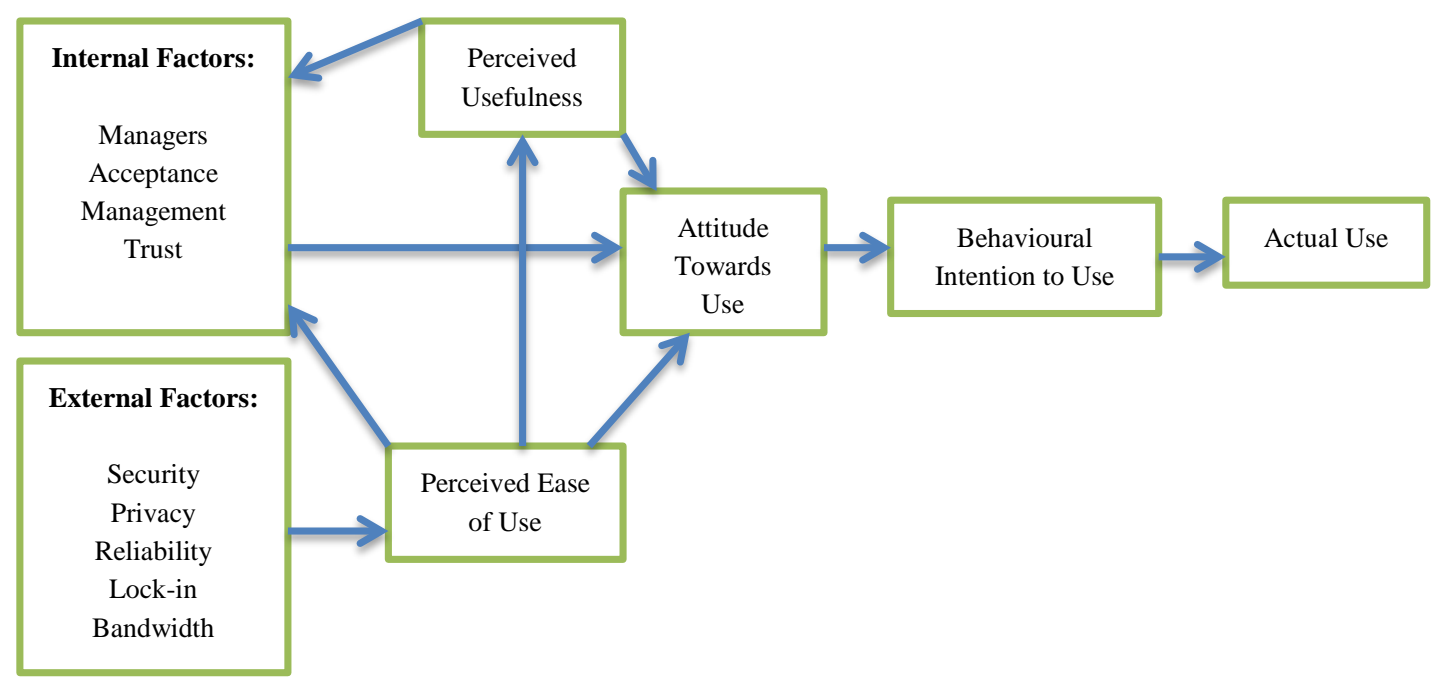

\subsection{Acceptance}

It is not easy to convince the decision makers in higher education to shift from one pattern to another. Cloud computing is a new IT Paradigm and it will change the familiar traditional pattern. Therefore, the users' (academics and top management) perception and acceptance will have an effect on adoption of cloud computing within institutions (Ketel, 2014).

\section{CLOUD COMPUTING ADOPTION MODEL IN HIGHER EDUCATION}

In this paper, we suggest an investigation towards challenges aforementioned. Technology Acceptance Model (TAM) (Davis, 2014) is adopted and integrated with additional factors in the literature to investigate further factors that influence the adoption of cloud computing in higher education institutions. TAM is the most influential extensions of Ajzen and Fishbein's Theory of reasoned action (TRA) (Ajzen and Madden, 1986). Based on an examination of computer-usage behaviour, Davis developed the TAM, which is designed to predict acceptance of information technologies and use on the job. It has been widely applied to variety of technologies and users. Several researchers have replicated TAM model to provide empirical evidence on the existing correlation between the usefulness and ease of use when using new technology. In addition, the researchers focused on testing the validity and reliability of the questionnaire instrument used by Davis and they found that the instrument had predictive validity for intent to use, self-reported usage and attitude toward use with different samples of users and different technologies (Hendrickson, Massey and Cronan, 1993; Albert, 1993; Szajna and Worth, 1994). The TAM addresses why users accept or reject the use of information technology due to external variables: in our model we categorise the external variable and divide them into two types:

1- Internal factors: consist of Managers, decision makers and academic expert's acceptance and their cultural and social believes and training needs to use cloud services in higher education institutions 'user's factors'.

2- External Factors: consist of Security, privacy, reliability, lock-in and Bandwidth 'Technological factors' that intervene and indirectly affect their attitude toward using it.

In this theory, the individual's attitude is based on two elements; the first one, 'perceived usefulness (PU)' which is the measurement of the person's beliefs about whether using the cloud services in Higher education would enhance their job performance. Perceived usefulness is an important element for investigating individual acceptance of a new technology (Ghorab, 1997; Anandarajan, Igbaria and Anakwe, 2002). According to Davies (Davis, 2014), individuals tend to use an electronic system when they believe that using the system will help in improving their job. It was confirmed that perceived usefulness factor has a strong impact on e-learning success (Park, 2009). So, in this study the users in universities such as IT staff and academic are more likely to use cloud education services if they feel that it is useful in education purposes. 
The second, 'perceived ease of use (PEOU)' is the measurement of the person's beliefs about using the cloud services in higher education institutions without expending extra effort. Perceived ease of use is defined as the extent to which the academic staff believe using cloud education emerging services would be free of effort. Perceived ease of use plays a key role in investigating individual acceptance of a new technology. TAM is the most widely applied model of user acceptance and usage. When users feel the technologies can be used in an easy way, it is more probable that they will adopt cloud services in their educational practices, so ease of use will affect universities staff attitude and behaviour. Therefore, the factor is selected in the model to examine the users' acceptance of using cloud services in their teaching as academic or to store records and leverage different services such PaaS for developers to design, implement, test, and run new software.

If the ease of use and usefulness of cloud computing services in higher education has been recognised by academics and top management personnel. This may lead to an increase the adoption rate of cloud computing in the education sector. Figure 3 above shows the proposed integrated model for this context. This will be used as a reference model in investigating the adoption factors in higher education institutions.

\section{CONCLUSION}

Cloud computing in higher education is still in its infancy compared to other industries. However, over time it will continually grow. The adoption of cloud computing may help universities to focus more on their main goals which are related to teaching and learning with minimum expenditure. Students and staff can rapidly and cost-effectively access various application platforms and pool of resources on-demand. Cloud computing services are useful and sometimes necessary to meet challenges and barriers to providing IT services in Universities.

Important challenges include security, privacy and vendor lock-in that can affect the adoption of cloud computing in education but there internal factors such as user's acceptance, user's trust, Internet efficiency and the educational management roles. This is an ongoing research of challenges that affects the adoption of cloud computing in higher education. Based on previous research, there is a lack of empirical studies investigating the low adoption of cloud computing in higher education institutions. Our future work will focus on investigating success factors for adoption of cloud computing in higher education using the proposed integrated reference model in this paper.

\section{REFERENCES}

Abdul Razak, S.F., 2009. Cloud computing in malaysia universities. 2009 Innovative Technologies in Intelligent Systems and Industrial Applications, CITISIA 2009, (July), pp.101-106.

Ajzen, I. and Madden, T.J., 1986. Prediction of goaldirected behavior: Attitudes, intentions, and perceived behavioral control. Journal of experimental social psychology, 22(5), pp.453-474.

Alabbadi, M., 2011. Cloud computing for education and learning: Education and learning as a service (ELaaS). 14th International Conference on Interactive Collaborative Learning (ICL2011), (September), pp.589-594.

Albert, H., 1993. Re-examining perceived ease of use and usefulness : A confirmatory factor analysi. 17(4), pp.517525.

Alshwaier, A., 2012. A New Trend for E-Learning in KSA Using Educational Clouds. Advanced Computing: An International Journal, 3(1), pp.81-97.

Anandarajan, M., Igbaria, M. and Anakwe, U.P., 2002. IT acceptance in a less-developed country: A motivational factor perspective. International Journal of Information Management, 22, pp.47-65.

Armbrust, M., Fox, A., Griffith, R., Joseph, A. and RH, 2009. Above the clouds: A Berkeley view of cloud computing. University of California, Berkeley, Tech. Rep. UCB, pp.07-013.

Buyya, R., Broberg, J. and Goscinski, A., n.d. Cloud Computing Principles and Paradigms.

David, W., 2013. Google Vs. Microsoft: Choosing Cloud Apps For Schools - InformationWeek.

Davis, F.D., 2014. Information Technology Introduction. 13(3), pp.319-340.

EarthBrowser, 2015a. EarthBrowser. [online] Available at: $<$ http://blog.earthbrowser.com/> [Accessed 12 Mar. 2015].

EarthBrowser, 2015b. EarthBrowser - Frequently Asked Questions. [online] Available at: $<$ http://www.earthbrowser.com/about/> [Accessed 12 Mar. 2015].

Ercan, T., 2010. Effective use of cloud computing in educational institutions. Procedia - Social and Behavioral Sciences, 2(2), pp.938-942.

Ghorab, K.E., 1997. The impact of technology acceptance considerations on system usage, and adopted level of technological sophistication: An empirical investigation. 
International Journal of Information Management, 17(4), pp.249-259.

Google, 2015. Google Apps for Education. [online] Available

$<$ https://www.google.com/work/apps/education/>

[Accessed 12 Mar. 2015].

Hendrickson, A.R., Massey, P.D. and Cronan, T.P., 1993. On the Test-Retest Reliability of Perceived Usefulness and Perceived Ease of Use Scales. MIS Quarterley, 17(2), pp.227-230.

Huang, X., 2012. An E-learning System Architecture based on Cloud Computing. Engineering and Technology, pp.7478.

IBM, 2014. IBM Cloud Academy - Overview - United States. Available at: $<$ http://www.ibm.com/solutions/education/cloudacademy/ us/en/> [Accessed 12 Mar. 2015].

Jay, G., 2014. Edutech for Teachers » Blog Archive » Guest Post: Google vs. Microsoft: Cloud Apps for Educators.

Ketel, M., 2014. E-Ieaming in a Cloud Computing Environment. pp.0-1.

Kurelovi, E.K., Rako, S. and Tomljanovi, J., 2013. Cloud Computing in Education and Student's Needs. MIPRO, Opatija, Croatia, pp.726-731.

Mathew, S., 2012. Implementation of Cloud Computing in Education - A Revolution. International Journal of Computer Theory and Engineering, 4(3), pp.473-475.

Mell, P. and Grance, T., 2011. The NIST Definition of Cloud Computing. Gaithersburg, MD: National Institute of Standards and Technology (NIST).

Mircea, M. and Andreescu, A., 2011. Using Cloud Computing in Higher Education: A Strategy to Improve Agility in the Current Financial Crisis. Communications of the IBIMA, 2011, pp.1-15.

Motta, G., Sfondrini, N. and Sacco, D., 2012. Cloud computing: An architectural and technological overview. Proceedings - 2012 International Joint Conference on Service Sciences, Service Innovation in Emerging Economy: Cross-Disciplinary and Cross-Cultural Perspective, IJCSS 2012, pp.23-27.

Park, S.Y., 2009. An Analysis of the Technology Acceptance Model in Understanding University Students' Behavioral Intention to Use e-Learning. Educational technology \& society, 12(3), pp.150-162.

Shakeabubakor, A., 2015. Cloud Computing Services and Applications to Improve Productivity of University
Researchers. International Journal of Information and Electronics Engineering, 5(2), pp.153-157.

Socratica, 2015. About Socratica. [online] Available at: $<$ http://www.socratica.com/about.html $>$ [Accessed 12 Mar. 2015].

Sultan, N., 2010. Cloud computing for education: A new dawn? International Journal of Information Management, 30(2), pp.109-116.

Szajna, B.B. and Worth, F., 1994. Software Evaiuation and Choice: Predictive Vaiidation of the Technoiogy Acceptance instrument. 18(3), pp.319-325.

VMware, 2015. Virtual Desktop Infrastructure (VDI) Features of Horizon (with View). [online] Available at: $<$ http://www.vmware.com/uk/products/horizonview/features.html> [Accessed 12 Mar. 2015]. 